\title{
Physical Properties of Soil and Its Implication to Slope Stability of Nungbi Khunou, NH-150, Manipur
}

\author{
Heisnam Bidyashwari ${ }^{*}$, Ramawadh Singh Kushwaha1, \\ Mairembam Chandra' ${ }^{2}$, Moirangthem Okendro ${ }^{2}$ \\ ${ }^{1}$ Department of Earth Sciences, Manipur University, Imphal, India \\ ${ }^{2}$ Department of Geology, Imphal College, Imphal, India \\ Email: *bidyashwariheisnam@gmail.com
}

How to cite this paper: Bidyashwari, H., Kushwaha1, R.S., Chandra, M. and Okendro, M. (2017) Physical Properties of Soil and Its Implication to Slope Stability of Nungbi Khunou, NH-150, Manipur. International Journal of Geosciences, 8, 1332-1343.

https://doi.org/10.4236/ijg.2017.811077

Received: August 10, 2017

Accepted: November 21, 2017

Published: November 24, 2017

Copyright $\odot 2017$ by authors and Scientific Research Publishing Inc. This work is licensed under the Creative Commons Attribution International License (CC BY 4.0).

http://creativecommons.org/licenses/by/4.0/

\section{(c) (i) Open Access}

\begin{abstract}
Determination of physical property of the soil helps in identification and classification of soil which includes analysis of particle size distribution, Atterberg limits, water content, specific gravity, phase determination and direct shear test. Water plays an important role in triggering landslides and slope failures. Increase of water content reduces the stability of slope. When the moisture content exceeds plastic limits, the slope begins to deform. Three soil samples are collected from the study area and the average bulk density, moisture content and specific gravity are 1.577, 37.032 and 2.434 respectively. Atterberg limit is the most distinctive properties of fine grained sediments and may be used to distinguish silts from clays. Plastic limits $\left(\mathrm{W}_{\mathrm{P}}\right)$, liquid limit $\left(\mathrm{W}_{\mathrm{L}}\right)$, shrinkage limit $\left(\mathrm{W}_{\mathrm{S}}\right)$ values of Nungbi Khunou are $26.236 \%$, 48\% and 9.4\% respectively. Plasticity index $\left(\mathrm{I}_{\mathrm{p}}\right)$, consistency index $\left(\mathrm{I}_{\mathrm{C}}\right)$ and liquidity index $\left(\mathrm{I}_{\mathrm{L}}\right)$ value is $21.764 \%, 0.379 \%$, and $60.623 \%$ respectively. From index properties value, the soil is highly plastic, stiff and semi-solid in nature. The soil sample falls under CI group in plasticity chart which indicates organic silt and clay soil with medium compressibility and plasticity. Phase determination and particle size distribution result in very high porosity and highly saturated soils which are well graded in nature. Slope and aspect map are prepared from DEM using ArcGIS. Slope is an important contributory factor to landslide, and slope reported from the sampling area indicates gentle slope. Aspect refers to the direction of the terrain faces which is influenced by component like vegetation, settlement, agriculture, precipitation, wind etc. Factor of safety (Fs) calculated from shear stress data is less than 1 indicating unstable slope. From the above finding, the study area may result in sudden and unpredictable failure due to volumetric changes in soil.
\end{abstract}




\section{Keywords}

Plasticity Index, Liquid Limit, Stiff Soil, Consistency Index

\section{Introduction}

Physical properties of soil, such as bulk density, cohesiveness and shear strength have been noted to affect stability of disturbed soil [1] [2] [3]. Other authors [4] have also used similar properties to characterize the nature and behaviour of soils. Problem soil comprises of expansive, soft clay, collapsible and dispersive soil which may induce slope failure, due to their distinct shrink-swell properties at various moisture content [5] [6]. Particle size and the distribution of pores within the soil matrix influence slope stability. Landslides are among the major hydro-geological hazards that affect large parts of the country. Northeast region, because of its fragile geological formation and structures, is highly prone to mass movement causing landslides. The major causes of the slides are both natural and anthropogenic. Geological formation along the road section between Ukhrul and Jessami along NH-150, belong to Disang and Barail groups. The constituent litho units are susceptible to weathering and erosion leading to slopes failure and mass wasting on moderate to large scale. The stratified nature of rocks, affected by deformation, plays an important role in causing landslides. No consideration of geological and geotechnical factors during construction considerably increases the incidences of landslides along the roads and hill slopes. Landslide hazard is defined as the probability of occurrence of landslides within a specific period of time and within a given area [7].

\section{Geology of the Study Area}

The present study area lies along national highway 150 between Ukhrul and Jessami (Figure 1). It is part of the mélange zone which belongs to the Indo-Myanmar Range (IMR). The study area is situated $38 \mathrm{~km}$ from Ukhrul town and belongs to Upper Disang Formation comprising rhythmic intercalation of fine grained sandstones, siltstones and shales (Plate 1(a)). Rocks are soft, fragile and highly weathered thereby converted to soil. The area is covered by a thick column of soil. Structural feature includes primary and secondary discontinuities in the rock such as bedding, foliation, joints, faults and fracture are very common in the nearby places. The sampling area has converted to terrace cultivated farm (Plate 1(b)) thereby leading instability of the slope.

\section{Material and Method}

In order to establish and characterize the problem nature of the slope material in terms of its implications for slope stability, a range of analysis were carried out at the geotechnical laboratory, Department of Earth Sciences, Manipur University. The analysis focused on the distribution of soil particles, Atterberg limit and 
shear strength. The percentage of clay size particles, in particular gives clear indication to the nature of the soils. The determination of Atterberg limit is an important component of soil analysis particularly in terms of its expansion at the different moisture and clay contents [8]. Such behavioural properties can be used to explain the susceptibility of slopes to various slope processes. The plasticity of the soil sample are further determined using the Unified soil classification system (USCS) plasticity chart which further enable classification of fine materials. Shearing strength in soil is the results of the resistance to movement at

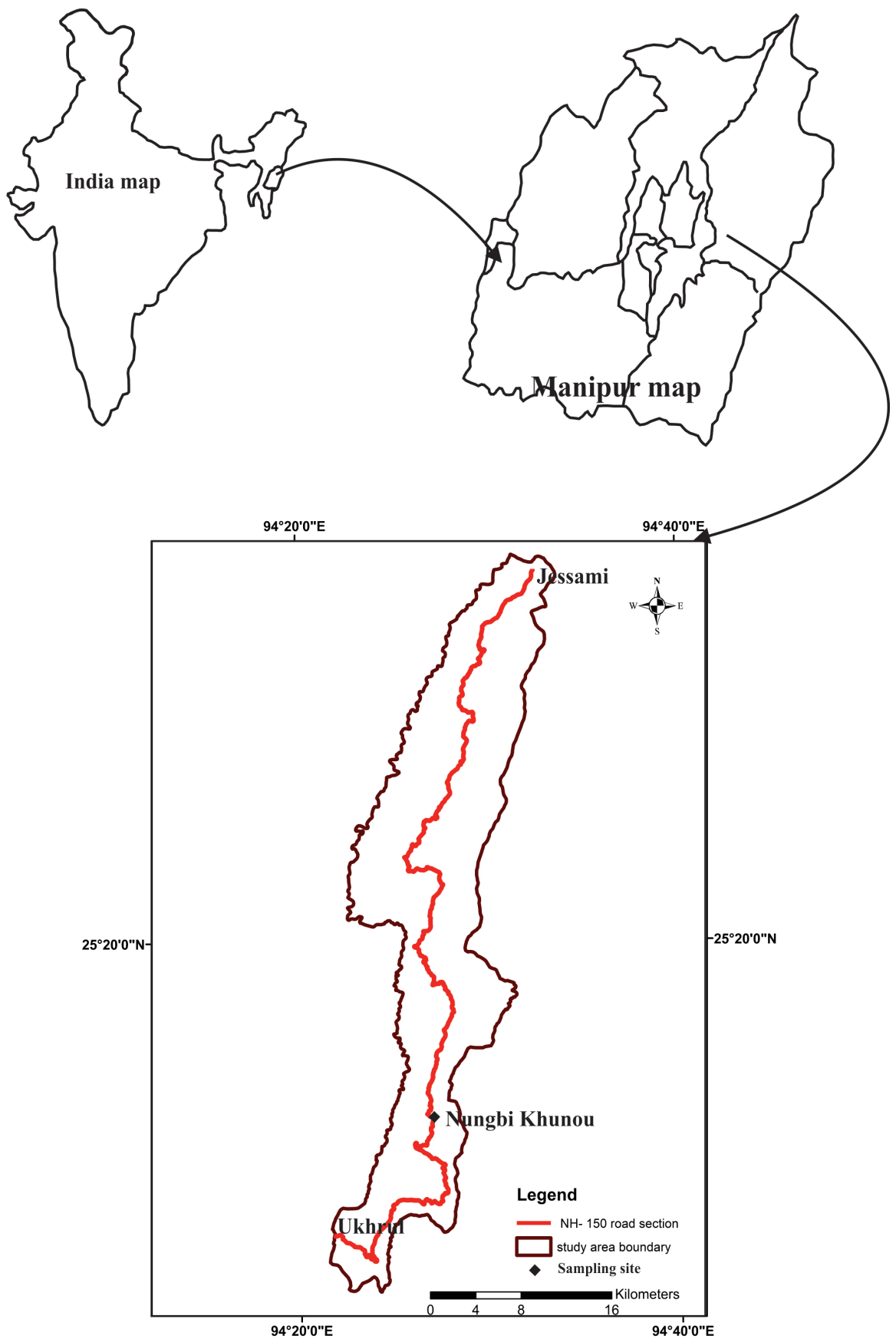

Figure 1. Location map of the study area. 

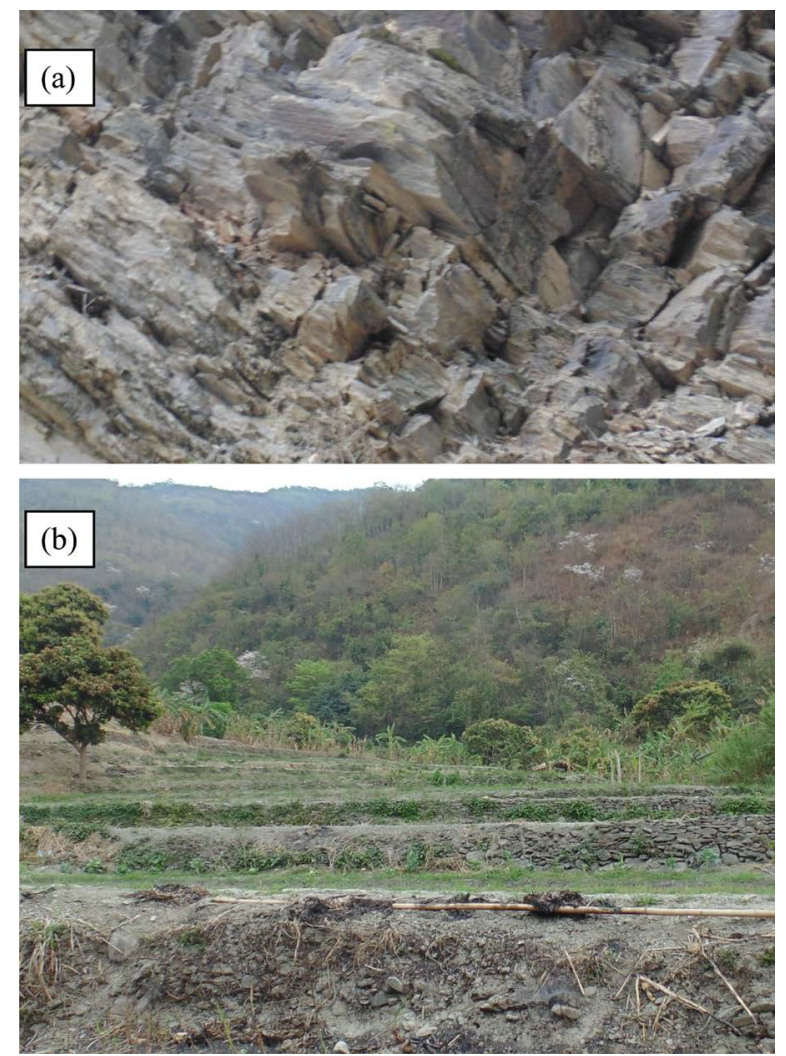

Plate 1. Field Photograph showing: (a) Intercalation of sandstone, siltstone and shale; (b) Terrace cultivation (sampling site).

inter particle contact due to particle interlocking. Direct shear test is performed to determine the shear strength of the soil, namely the cohesion $(C)$ and the internal angle of friction $(\Phi)$ values. Factor of safety $\left(F_{s}\right)$ is determined by using circular failure Charts (direct shear test approach).

\section{Results}

\subsection{Result of Soil Index Properties}

The moisture content $(W)$ is defined as the ratio of weight of water $\left(W_{L}\right)$ to the weight of the soil solid $\left(W_{d}\right)$ in a given mass of soil which is usually expressed as

$$
W=\frac{W_{L}}{W_{d}} \times 100(\%)
$$

Measurement and recording of water content have done for those materials that were transported and stored in a sealed condition, providing confidence that the materials had not dried out between the time of sampling and testing in the laboratory. For the present work, oven drying method is used for determining the moisture content of soil sample.

The bulk density or the nature of in-situ weight of a soil in a unit volume, is expressed as

$$
\rho=\frac{M}{V}
$$


where $M=$ total mass of the soil, $V=$ volume of the soil.

The bulk density is determined by using a core cutter and a weight balance.

Specific gravity of soil from the sliding zone is determined by using $50 \mathrm{ml}$ density or specific gravity bottle. Data for moisture content, bulk density, specific gravity of the soil sample is shown in Table 1.

Three Phase determination of soil is important in identifying soil character. Generally soil has three constituents which do not occupy separate space but are blend together forming a complex material. The interrelationships of the weights and volume of the three phases are important since they help in understanding the natural character of a soil. The volume of air $(V a)$, water $(V w)$ and soil $(V s)$ are calculated from the measured index properties such as bulk density $(\rho)$, specific gravity $(\mathrm{G})$ and the natural moisture content $(W)$. The total volume of the different element is assumed to be a unit volume. Volume relationship of three phases of soil from Nungbi Khunou Sample is shown in Table 2. Porosity, void ratio, degree of saturation, dry density and submerge density of the soil sample can be calculated from the values of three phases and is given in Table 3 below.

\subsection{Soil Particle Distribution}

Gradation curve for the representative soil sample of the study area is determined using both hydrometer and sieve methods. The results of the analysis are plotted to get a particle size distribution curve with the percentage finer $\mathrm{N}$ as the Ordinate and the particle diameter as the abscissa plotted on a logarithmic scale. The particle size distribution curve gives us an idea about the type and gradation of the soil. A curve situated higher up or to the left represent a relatively fine grain soil while a curve situated to the right represent a coarse grain soil. A soil is said to be well graded when it has good representation of particles of all sizes. On the other hand, a soil is said to be poorly graded if it has an excess of certain particles and deficiency of other or if it has most of the particles of about the

Table 1. Physical parameters of the soil sample.

\begin{tabular}{cccc}
\hline Sample & Moisture content $(W) \%$ & Bulk density $(\rho) \mathrm{g} / \mathrm{cc}$ & Specific gravity $(\mathrm{G})$ \\
\hline Nungbi Khunou & 37.032 & 1.577 & 2.434 \\
\hline
\end{tabular}

Table 2. Volume relationship of three phases of soil sample.

\begin{tabular}{cccc}
\hline Location & Volume of soil $(V s) \%$ & Volume of water $\left(V_{w}\right) \%$ & Volume of air $(V a) \%$ \\
\hline Nungbi Khunou & 47.28 & 42.62 & 10.10 \\
\hline
\end{tabular}

Table 3. Parameters derived from three phase analysis.

\begin{tabular}{ccccccc}
\hline Sample no. & $\begin{array}{c}\text { Porosity } \\
(\eta) \%\end{array}$ & $\begin{array}{c}\text { Void ratio } \\
(\mathrm{e})\end{array}$ & $\begin{array}{c}\text { Degree of } \\
\text { saturation }\left(\rho_{s}\right) \%\end{array}$ & $\begin{array}{c}\text { Dry density } \\
\left(\rho_{d}\right) \mathrm{g} / \mathrm{cc}\end{array}$ & $\begin{array}{c}\text { Saturated } \\
\text { density } \\
\left(\rho_{\text {sat }}\right)\end{array}$ & $\begin{array}{c}\text { Submerge } \\
\text { density } \\
\left(\rho^{\prime}\right)\end{array}$ \\
\hline $\begin{array}{c}\text { Nungbi } \\
\text { Khunou }\end{array}$ & $\begin{array}{c}52.72 \\
\text { (very high) }\end{array}$ & $\begin{array}{c}1.115 \\
\text { (very high) }\end{array}$ & $\begin{array}{c}80.842 \\
\text { (highly saturated) }\end{array}$ & $\begin{array}{c}0.993 \\
\text { (very low) }\end{array}$ & 1.577 & 0.577 \\
\hline
\end{tabular}


same size it is known as uniformly graded soil. From the graph (Figure 2) uniformity coefficient or coefficient of uniformity $\left(C_{u}\right)$ is calculated, which is a measured of particle size range given by the ratio of $D_{60}$ and $D_{10}$ sizes. The shape of the particle size curve is represented by coefficient of the curvature $C_{c}$ given by ratio of square of $D_{30}$ the product of $D_{10}$ and $D_{60}$ :

$$
C_{u}=D_{60} / D_{10}=5 / 0.6=8.33 ; C_{c}=\left(D_{30}\right)^{2} / D_{10} \times D_{60}=5.29 / 3=1.763
$$

From the gradation curve the value of $C_{u}$ and $C_{c}$ is determined which indicates well graded sand with nearly $5 \%$ clay size particles.

\subsection{Atterberg Limits}

Atterberg limits or consistency limits means the relative ease with which soil can be deformed and denotes the degree of firmness of the soil. In order to determine the soil behaviour in respond to water content and its implication to landslide occurrence Atterberg limits were calculated and shown in Table 4.

Liquid limit of the study area is $48 \%$ indicating the high expansion potential of the soil. The moisture content of the soil is 37.032 which exceed the plastic limit of the soil. In this condition the deformation of the slope is possible and ultimately resulting the slope to an unstable condition. The plasticity index of a soil is commonly correlated with the expansion and residual angle of internal

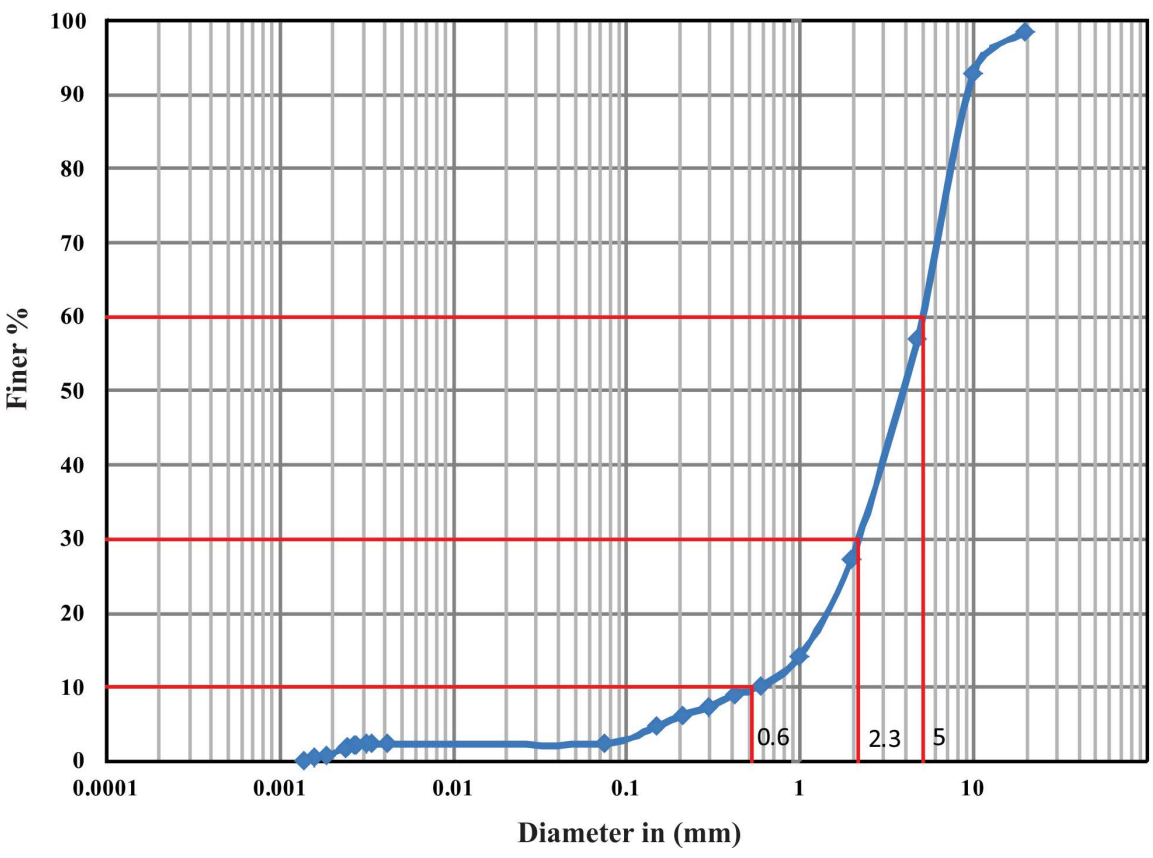

Figure 2. Particle size distribution curve of soil sample.

Table 4. Data for Atterberg limits determination.

\begin{tabular}{ccccccc}
\hline Sample & $\begin{array}{c}\text { Liquid limit } \\
\left(\mathrm{W}_{\mathrm{L}}\right) \%\end{array}$ & $\begin{array}{c}\text { Plastic limit } \\
\left(\mathrm{W}_{\mathrm{P}}\right) \%\end{array}$ & $\begin{array}{c}\text { Shrinkage limit } \\
\left(\mathrm{W}_{\mathrm{S}}\right) \%\end{array}$ & $\begin{array}{c}\text { Plasticity } \\
\text { index }\left(\mathrm{I}_{\mathrm{P}}\right)\end{array}$ & $\begin{array}{c}\text { Liquidity } \\
\text { index }\left(\mathrm{I}_{\mathrm{L}}\right) \%\end{array}$ & $\begin{array}{c}\text { Consistency } \\
\text { index }\left(\mathrm{I}_{\mathrm{C}}\right)\end{array}$ \\
\hline $\begin{array}{c}\text { Nungbi } \\
\text { Khunou }\end{array}$ & 48 & 26.236 & 9.4 & 21.764 & 60.623 & 0.327 \\
\hline
\end{tabular}




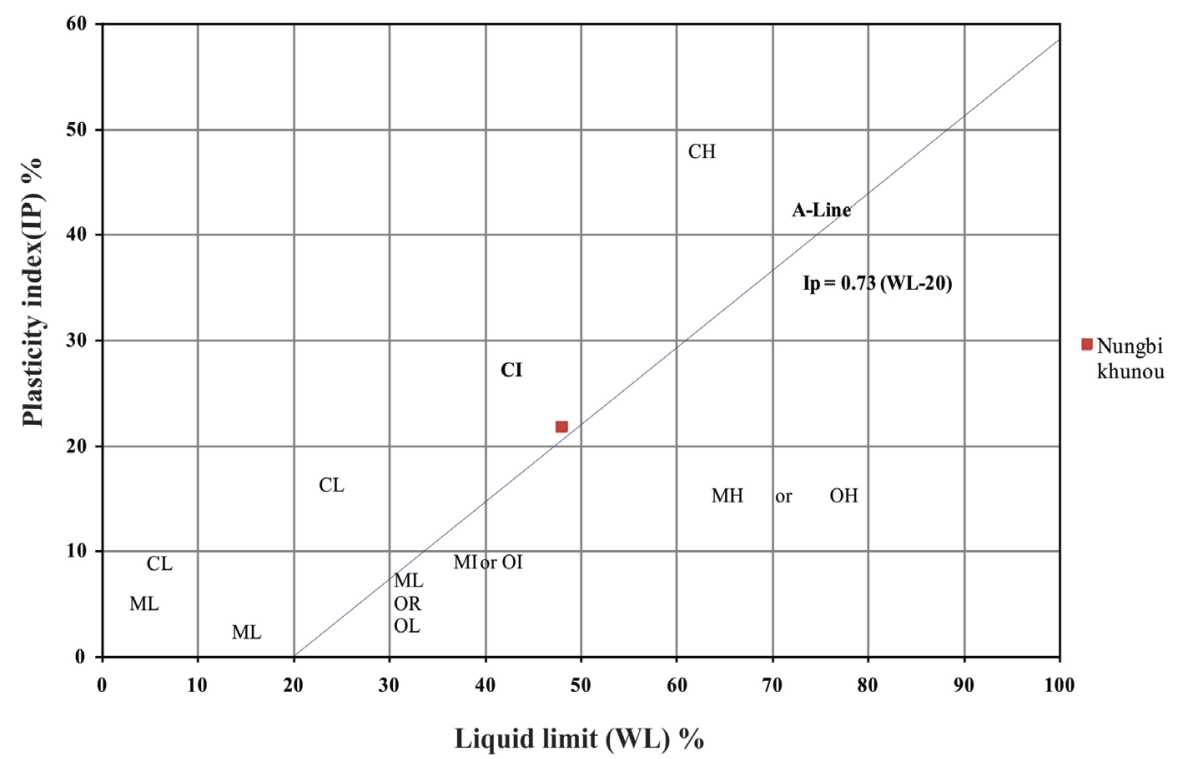

Symbols stands as detailed below:

$M$ - Inorganic Silt and very fine sands,

C- Inorganic clays,

O - Organic Silts and clays,

L - Silts and clays of medium compressibility and medium plasticity,

$H$ - Silts and clays of high compressibility and high plasticity.

Figure 3. Plasticity chart of the soil.

friction for drained field condition [9]. The greater the plasticity index, the more likely the soil is to become unstable and plastic under field condition [10]. The plasticity index of the site indicates highly plastic soil. The soil is classified as semi solid and stiff from its consistency and liquidity index value.

Plasticity chart is used to classified fine grains. Many properties of clay and silt can be correlated with the Atterberg limit by means of plasticity chart [11]. In the plasticity chart the ordinate represent the plasticity index and the abscissa the corresponding liquid limit. The chart is divided into different region. The A-line divides inorganic clay from silt and organic soil. Plasticity chart for the soil sample (Figure 3) falls under CI group which indicate organic silt and clay soil with medium compressibility and plasticity.

\subsection{Shear Strength and Factor of Safety (Fs)}

Plots of shear strength versus normal stress were used to compute the angle of internal friction and cohesion which were then used to calculate the factor of safety of the slope. Generally landslides occur when the disturbing/driving force (FD), which is chiefly resulted from the self-weight of the slope forming materials exceeds the resisting force (FR) given by the shear strength of the materials. So, the factor of safety of a slope is the ratio of resisting forces to driving forces, i.e. $\mathrm{F}=$ resisting forces/driving forces. If the factor of safety is less than or equal to 1 (i.e., $\mathrm{F} \leq 1$ ), the slope will fail because driving forces will equal or exceed the resisting forces. If $\mathrm{F}$ is significantly greater than 1 , the slope will be quite stable. 
However, if F is slightly greater than 1 , small disturbances may cause the slope to fail. Direct Shear Test data is used in determination of shear strength of soil and factor of safety. Direct shear test is generally done in-situ soil sample in laboratory.

Parameters for calculating factor of safety are:

a) Average Slope angle-It is the average angle between horizontal surface and slope face where sliding occurs. It can be obtained from field observation.

b) Height of the slope $(\mathrm{H})$ - It is the vertical height of the slope face measured from the toe of the slope up to highest point of phreatic surface. Generally it is represented by $\mathrm{H}$.

c) Unit weight of the soil $(\gamma)$ - It is defined as the weight per unit volume. Hence it will be represented in terms of $\mathrm{kN} / \mathrm{m}^{3}$.

$$
\text { Thus, } \begin{aligned}
\gamma=\frac{\text { Weight of the soil }}{\text { Volume of the soil }}\left(\mathrm{kN} / \mathrm{m}^{3}\right) \\
=\operatorname{Bulk} \text { density }(\rho) \times 9.81\left(\mathrm{kN} / \mathrm{m}^{3}\right)
\end{aligned}
$$

d) Moisture Content (W)-It is the difference in weight between wet soil and dry soil gives the moisture content of the soil sample.

e) Cohesion (c) - It is the innate "stickiness" of a material, the attraction of its molecules for each other. For example, clay and granite are both cohesive. Dry sand, on the other hand is cohesion less, that is, its cohesion is zero.

f) Angle of internal friction $(\Phi)$-Internal friction is due to the grains of the material rubbing against each other the friction depends on slickness of the particular materials, hardness of the grain being force against each other by gravity.

Normal stress $(\sigma)$ and Shear stress $(\tau)$ parameters of the soil samples of the slide site can be obtained from stress strain curve of soil samples by taking the highest peak point from the load-displacement curve. Then Normal stress $(\sigma)$ and Shear stress $(\tau)$ parameters are plotted on the Normal stress \& Shear stress graph (Figure 4) to obtain the value of cohesive strength (C) and internal frictional angle $(\varphi)$ of the soil sample of slide site.

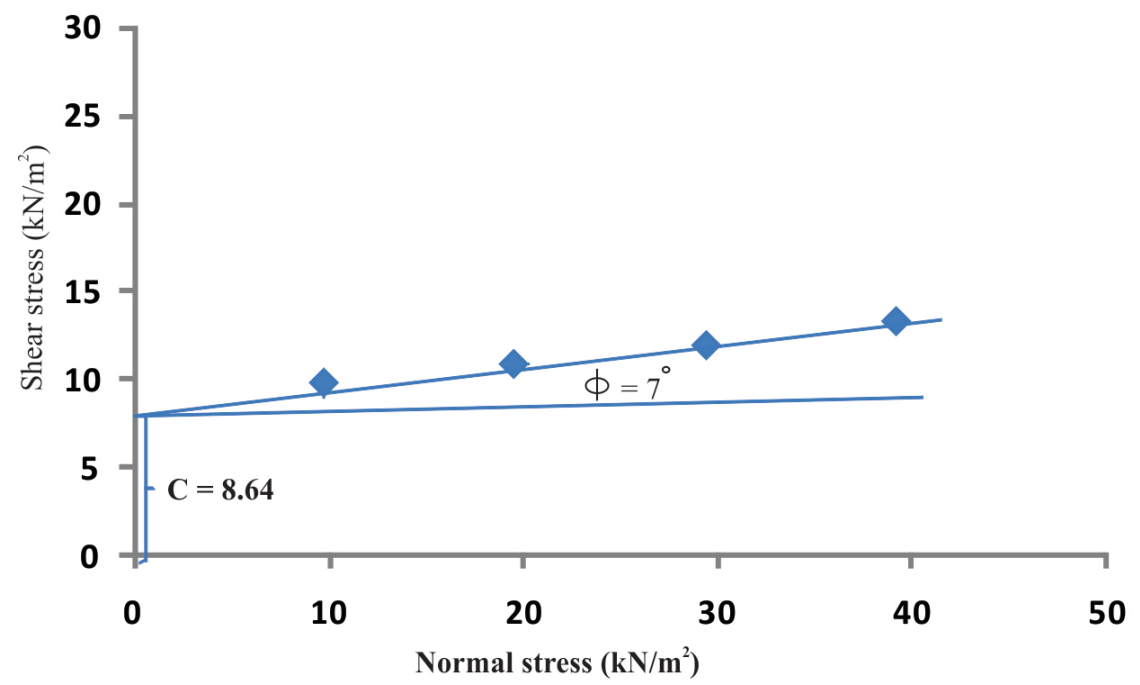

Figure 4. Normal and shear strength graph of soil sample. 
Detailed input parameters for determination of factor of safety (Fs):

Average Slope angle $=25^{\circ}$;

Height of the slope $(\mathrm{H})=80 \mathrm{~m}$;

Unit weight of soil $(\gamma)=15,470 \mathrm{~N} / \mathrm{m}^{3}$;

Cohesion (c) $=8640 \mathrm{~N} / \mathrm{m}^{2}$;

Angle of internal friction $(\varphi)=7^{\circ}$;

Moisture content $=37.032 \%$.

The Circular Failure Chart [12] has been chosen for the derivation of Factor of safety $(\mathrm{F})$. The value of dimensionless ratio $(\mathrm{C} / \gamma \cdot \mathrm{H} \cdot \tan \varphi)$ is 0.0568 , calculated from the data obtained from field observations and tests conducted. This value is marked on the peripheral arc (outer circular scale) of the failure chart for the corresponding ground water condition. The radial line from the outer circular scale is then followed to the particular curve for slope angle. The corresponding value of $\tan \varphi / \mathrm{F}$ (Y-intercept) and $\mathrm{C} / \gamma$. H.F (X-intercept) is found out by projecting horizontally and vertically on two axes of the chart. Hence the $\mathrm{F}$ value is calculated as average of the above two F values (obtained from X\&Y intercepts).

From the circular failure chart we have the Y-intercept value is 0.29 (approx.) and putting the value of $\tan \varphi / f$ to 0.029 the value of $\mathrm{F}$ can be calculated as

Tan $\varphi / \mathrm{F}=0.29$

Or, $\mathrm{F}=\tan 7^{\circ} / 0.29$

$=0.123 / 0.29$

$=0.423$

Similarly obtaining X-intercept value of 0.018 (approx.) and putting the values of $\mathrm{C}, \gamma$ and $\mathrm{H}$

We get, $\mathrm{C} /(\gamma \times \mathrm{H} \times \mathrm{F})=0.018$

$$
\begin{aligned}
\mathrm{F} & =\mathrm{C} /(0.018 \times \gamma \times \mathrm{H}) \\
& =8640 / 0.018 \times 15,470 \times 80 \\
& =0.388
\end{aligned}
$$

Factor of safety $=(\mathrm{F}$ value along $\mathrm{y}$ intercept $+\mathrm{F}$ value along $\mathrm{x}$-intercept $) / 2$

$$
\begin{aligned}
& =(0.423+0.388) / 2 \\
& =0.405
\end{aligned}
$$

The Fs value of the soil sample is found to be 0.405 which is less than 1 , indicating vulnerable area to landslide.

\subsection{Slope and Aspect}

Slope is an important contributory factor to landslide but the slope alone doesn't cause landslide and other factors like rock types, structure, landuse, etc. also contribute, as a result landslides occur even in gentle slope as well. The slope map of the study area is prepared from DEM data. The slope of the area is classified into 5 categories in degree as $0-15,16-25,26-35,36-45$, and $>45$. Generally moderate slope have higher frequency of landslide. But the landslide reported from the sampling area indicate gentle slope, where terrace cultivation is practicing just above the highway. The Slope map is shown in Figure 5. 


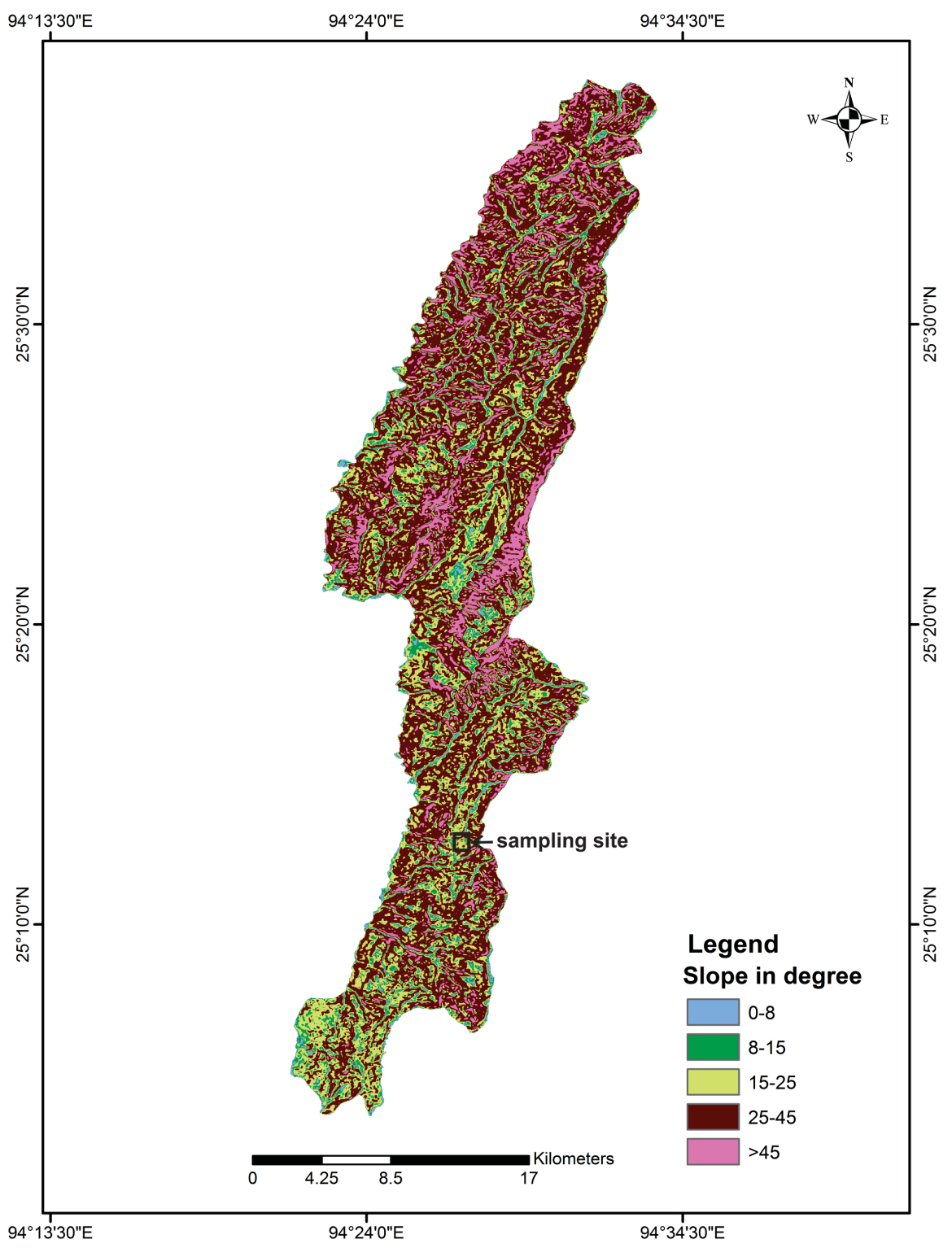

Figure 5. Slope map of the study area.

Aspect refers to the direction to which a mountain slope faces which is generally express in term of degree from $0^{\circ}$ to $360^{\circ}$. Aspect is influence by component like vegetation, settlement, agriculture, precipitation, wind etc. The direction of the aspect was derived in $0^{\circ}$ is true north; $90^{\circ}$ aspect is to the east. The aspect map is shown in Figure 6.

\section{Conclusion}

The study area is part of Indo-Myanmar mobile belt and composed mainly of Disangshales, Barail sandstone and Siltstone. Being a thrusting zone, rock of the region is highly deformed, jointed and prone to weathering. During heavy monsoon, soft lithology like shale and mudstone become mud and silt and susceptible to slide. This study determined the physical property of soil and its implica- 


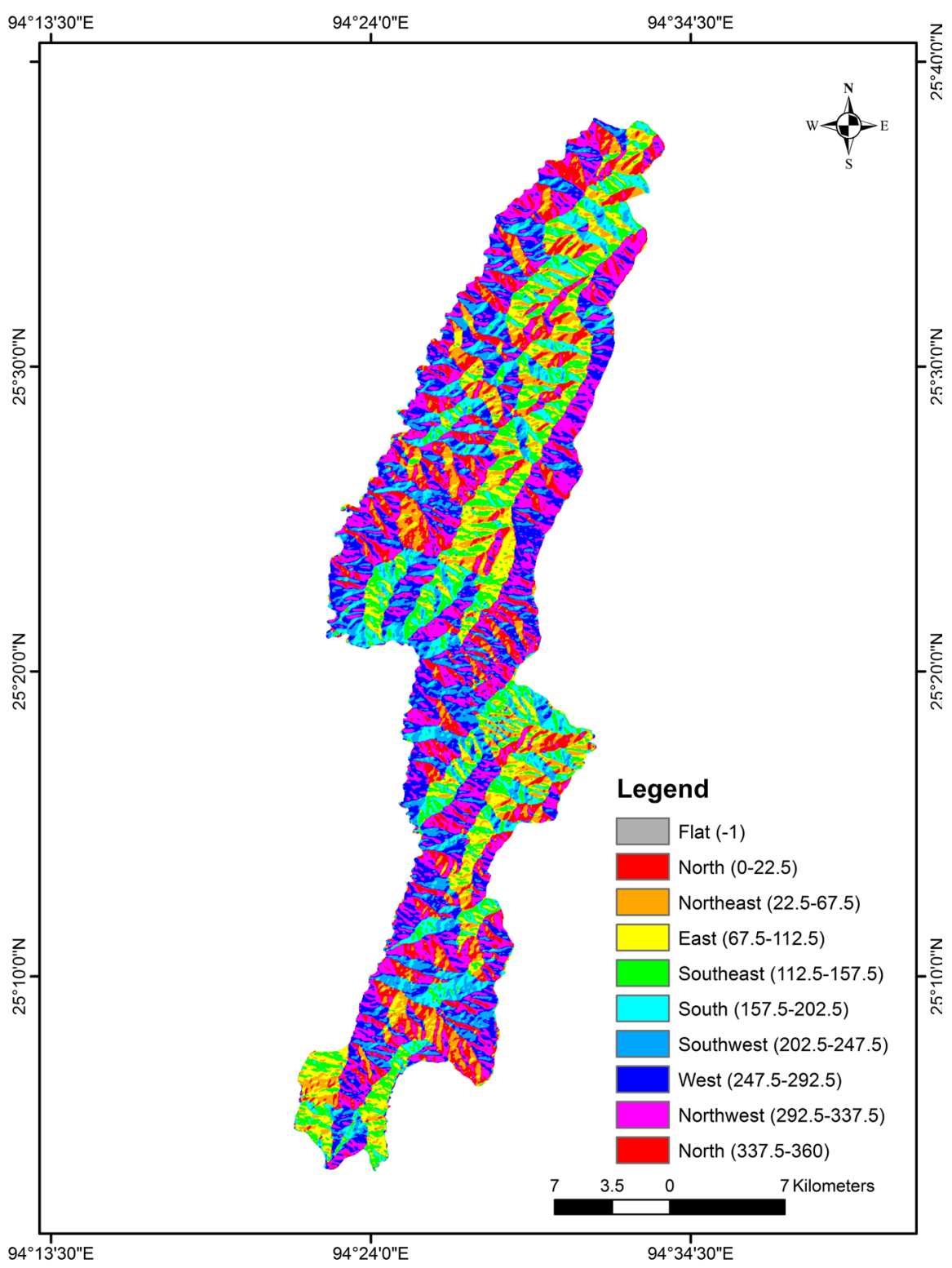

Figure 6. Aspect map of the study area.

tion to landslide occurrence. The soil at the site is characterized by low clay particle size content with medium compressibility and plasticity. As its moisture content exceeds the plastic and shrinkage limit, it indicates that the soil is in semi solid state and has a tendency to deform under its weight. From the particle, size determination curve the soil is found to be well-graded sand and its factors of safety indicate the sampling area prone to landslide as its value is less than 1. Generally, moderate slope have higher frequency of landslide. But the landslide reported from the sampling area indicates gentle slope. The studies reveal that slope are not the major controlling factor, lithology and structure are the controlling factor for landslide. Terrace cultivation and resultant water logging in the study area cause slide and damage of road during the monsoons. The result of this study will be useful for undertaking mitigative measures and fur- 
ther developmental activities in the area. Further analyses, including preparation of landslide hazard zonation map, landslide susceptibility map, rock mass rating, slope mass rating etc. are to be done to know the detailed problem and to provide effective mitigation measures.

\section{References}

[1] Sidle, R.C., Pearce, A.J. and Loughlin, C.L.O. (1985) Hillslope Stability and Land Use. American Geophysical Union, Washington DC, 125 p. https://doi.org/10.1029/WM011

[2] Kitutu, M.G., Muwanga, A., Poesen, J. and Deckers, J.A. (2009) Influence of Soil Properties on Landslide Occurrence in Bududa District, Eastern Uganda. African Journal of Agricultural Research, 4, 611-620.

[3] Zung, A.B., Sorensen, C.J. and Winthers, E. (2009) Landslide Soils and Geomorphology in Bridger/Teton Forest Northwest Wyoming. Physical Geography, 30, 501-516. https://doi.org/10.2747/0272-3646.30.6.501

[4] Mugagga, F., Kakembo, V. and Buyinza, M. (2011) A Characterisation of the Physical Properties of Soil and the Implications for Landslide Occurrence on the Slopes of Mount Elgon, Eastern Uganda. Natural Hazards, 60, 1113-1131. https://doi.org/10.1007/s11069-011-9896-3

[5] Van der Merwe, D.H. (1964) The Prediction of Heave from the Plasticity Index and the Percentage Clay Fraction of Soils. The South African Institution of Civil Engineering, 6, 103-107.

[6] Baynes, F.J. (2008) Anticipating Problem Soil on Linear Project. In: Conference Proceedings on Problem Soils in South Africa, Midrand, 3-4 November 2008, 9-21.

[7] Varnes, D.J. (1984) Landslide Hazard Zonation-A Review of Principles and Practice. IAEG Commission on Landslides, Paris, 63.

[8] Selby, M.G. (1993) Hillslope Materials and Processes. Oxford University Press, New York.

[9] Gibson, R.E. (1953) Experimental Determination of True Cohesion and True Angle of Internal Friction in Clays. Proceedings of the 3rd International Conference on Soil Mechanics and Foundation Engineering Division, ASCE, 85, 67-79.

[10] David Jr., K.W. and Horace, R.C. (1967) Geological Aspects of a Recent Landslide in Vinton County, Ohio. The Ohio Journal of Science, 67, 65-74.

[11] Casagrande, A. (1932) Research on the Atterberg Limits of Soil. Public Roads, 13, 121-136.

[12] Hoek, E. and Bray, J.W. (1981) Rock Slope Engineering. The Institution of Mining and Metalurgy, London, $358 \mathrm{p}$. 